\title{
An Examination of the Physio-mechanical Properties of Rock Lump and Aggregates in Three Leading Quarry Sites Near Accra
}

\author{
Joseph Ignatius Teye Buertey ${ }^{1,}$, Felix Atsrim $^{1}$, Samuel Wilberforce Offei ${ }^{2}$ \\ ${ }^{1}$ Department of Built Environment, Pentecost University College, Accra, Ghana \\ ${ }^{2}$ Department of Project Management, Accra Institute of Technology, Accra, Ghana
}

Email address:

jbuert@yahoo.co.uk (J. I. T. Buertey)

${ }^{*}$ Corresponding author

\section{To cite this article:}

Joseph Ignatius Teye Buertey, Felix Atsrim, Samuel Wilberforce Offei. An Examination of the Physio-mechanical Properties of Rock Lump and Aggregates in Three Leading Quarry Sites Near Accra. American Journal of Civil Engineering. Vol. 4, No. 6, 2016, pp. $264-275$. doi: 10.11648/j.ajce.20160406.11

Received: May 30, 2016; Accepted: July 26, 2016; Published: September 2, 2016

\begin{abstract}
In recent times, there has been an increasing indiscrimination in the choice of aggregate for the casting of concrete in the construction industry. The nearest available material is used without looking into its properties and strength. The source of aggregates and its physio-mechanical properties have an effect on the final product depending on the design mix. This study focusses on the determination of dry density, water content of rock materials, porosity, compressive strength of parent rock lumps material, rock aggregates and the grading of aggregates. Samples were picked from three leading quarries near Accra, Ghana and were tested quantitatively at the laboratory. Analysis shows that air spaces in rock lump samples with valued percentages varied from $29 \%$ to $34 \%$ and $41 \%$ for igneous, sedimentary and metamorphic rocks respectively, with a direct proportional effect on the water content of the rock lump. Invariably, the dry density for sampled igneous, sedimentary and metamorphic rocks lump varied from $1.12 \mathrm{~g} / \mathrm{cm}^{3}$ to $1.57 \mathrm{~g} / \mathrm{cm}^{3}$ and $2.03 \mathrm{~g} / \mathrm{cm}^{3}$ respectively. There was a direct correlation between the impact resistance and load resistance results of the samples. Igneous rock recorded the highest impact resistance of $802 \mathrm{~mm}$ followed by sedimentary and then metamorphic rocks with $602 \mathrm{~mm}$ and $201 \mathrm{~mm}$ respectively with a corresponding load resistance of $57 \mathrm{kn}, 29 \mathrm{kn}$ and $13 \mathrm{kn}$. The studies revealed rock aggregate moisture contents as $8.1 \%, 7.6 \%$ and $10.7 \%$ translating into its water absorption and porosity of $10.25 \%, 14.11 \%$ and $7.55 \%$ for igneous, sedimentary and metamorphic rocks respectively. The laboratory results with respect to grading of the aggregates for particle size distribution shows that sedimentary crush rocks showed a well graded particle size distribution, best suited for concrete works. Based on comparative laboratory analysis of the physio-mechanical properties of the three rocks, igneous rocks showed properties best suited for concrete mix design, whilst metamorphic rock samples proved to be the poorest.
\end{abstract}

Keywords: Concrete, Physio-mechanical Properties, Rock Sample, Aggregates, Strength, Construction

\section{Introduction}

Concrete is a mixed component typically comprising four basic construction materials: coarse aggregate, fine aggregate, cement, water and sometimes admixtures. According to [1], coarse aggregate generally takes approximately $60-75 \%$ of the total volume of the concrete, hence the need to examine the physical and mechanical characteristic effect on the strength of the concrete. The important aggregate features to be considered in the investigation are the size, shape, surface texture, strength, stiffness, soundness and durability. The overall characteristic texture with respect to the depths of the parent rock also affects the strength. Aggregates, a mixture component of various sizes of stone or rock particles in contact with each other, can either be quartz, sandstone or quartzite in addition to blast furnace slag, or recycled concrete fragments. From [2], particles with a diameter greater than $3 / 16$ in. or $5 \mathrm{~mm}$ (retained on the No. 4 sieve) are typically classified as coarse aggregate, while smaller particles (passes through the No. 4 
sieve) are called fine aggregate. In a Portland cement concrete mix, coarse and fine aggregates typically make up $70 \%$ to $90 \%$ of the total volume of structural concrete [2].

The physio-mechanical properties of these aggregates however have an effect on the strength properties of aggregates being produced. Knowledge of these properties would inform one on the design mix to be applied and the type of aggregate to be used on prospective projects. When water is added to mixed component to form concrete, chemical reactions takes place between the binding material and the coarse aggregate as a result of chemical and physical content of the rocks during its process of formulation. Concrete is produced from different types of aggregate, and this impacts different property to the resulting concrete. The most important property of concrete is its compressive strength which elevates the actual state and strength of the concrete. This research paper reports the tests undertaken to investigate the physio-mechanical properties of parent rocks and rock aggregates from three quarry sites near Accra and its possible effect of the design mix of concrete.

\section{Factors Affecting the Behavior of Aggregates}

\subsection{Shape}

Aggregate particle shape can usually be classified into one of two types, rounded or angular. Natural aggregates, which are typically found on coastlines or in riverbeds, are typically smooth in texture and round in shape due to weathering. Mechanically ground by machines, crushed aggregates from the parent rock on the other hand are commonly angular in shape and have a rough surface texture. The shape of the aggregate usually affects both the strength and workability of concrete [3].

\subsection{Surface Texture}

Surface texture, is related to a number of factors, including particle mineralogy, surface roughness and the amount of moisture and dust adhering to the aggregate surface. Surface texture influences chemical inertness, polishing resistance and most importantly, bitumen and cement adhesion. Surface textures are typically classified as either rough or smooth and will influence the tenacity with which the cement paste adheres to the coarse aggregate. Aggregates with rough surface texture bond more firmly with cement paste than relatively smooth rounded materials[3]. While these characteristics are important for a quality concrete mixture, it should be noted that good adhesion properties are primarily associated with a certain grade of aggregates [3].

The figure 1, below show the various expected shapes of a crush rock from any quarry, these range from angular in (a), rounded in (b), flaky in (c), elongated in (d) and flaky and elongated in (e). The nature, shape and mineralogical content of the coarse aggregate has an effect on the strength of normal mixed concrete [3].

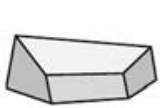

(a)

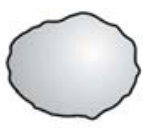

(b)

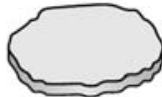

(c)
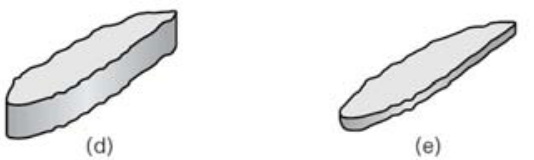

(e)

Source: [4]

Figure 1. Varied shapes of aggregates.

\subsection{Weatherability}

Weatherability is the ability of an aggregate to resist the effects of weathering. Engineers often use three parameters that relate to weatherability. These parameters are soundness, abradability and durability. Soundness is the vaguest of these three parameters. Originally, it reflected the thought that an unsound, or porous, aggregate would produce a very dull, thud-like sound when struck by a hammer, whereas a sound, or strong, material would produce a ringlike sound. Currently, it relates to the extent to which aggregates will disintegrate during salt crystallization in the sulfate soundness test of the American Society for Testing and Materials (4). Abradability is a more specific term referring to failure that may occur due to wear and tear, or in the case of pavements, to wear and breakdown resulting from the impact of tires on the aggregate over time and durability. Durability is a terms that can refer to the resistance of the aggregate to any type of failure during its life period, though it should be properly restricted to moisture- and temperaturedependent, rather than load related processes [5].

\subsection{Gradation of Coarse Aggregates}

Particle size and gradation of the aggregate have a significant effect on the behavior of a concrete mix, affecting its economy, workability and strength. For a given water/cement ratio $(\mathrm{w} / \mathrm{c})$, the amount of water to be added is inversely proportional to the maximum aggregate size. The use of larger sized coarse aggregates decreases the amount of cement paste required to bond the particles, which explains why concrete mixes with high quantities of coarse aggregates are less workable and very difficult to finish. Conversely, the use of finer particles entails the use of more cement in order to maintain constant aggregate/cement ratio, which at the same time decreases the workability of the concrete, even as it improves its finishing [6]. According to maximum aggregate size typically ranges between $0.75 \mathrm{~mm}$ and $1.5 \mathrm{~mm}$., while about $25 \%$ to $45 \%$ of the total aggregate content consists of fine aggregate. Special mixes of concrete may require aggregates outside these ranges. Aggregate mixtures can be broadly classified in terms of their particle size distribution (PSD) into three types: dense graded mixes, open graded mixes and gap graded mixes [3].

Dense-graded aggregate mixes can also be called wellgraded, continuous-graded, or straight line-graded mixes. These types of mixes are characterized by an even 
distribution of particle sizes, such that finer grains can fill the voids between larger ones. Dense-graded mixes have reduced void space leading to increased shear strength and must be placed in thicker lifts [3], [5].

Open-graded mixes, also known as no-fines or harshlygraded mixes, contain an even mixture of various coarse particle sizes but little or no void filling fines. Consequently, they depend heavily on friction between interlocking angular and rough textured coarse fragments for strength. Moreover, the increased void space allows moisture to drain easily, which explains why open-graded aggregates are commonly used in roadway bases. [3].

Gap-graded aggregate mixes, also known as skip-graded which are mixes of an intermediate size fraction, generally either coarse sand or fine gravel. Leaving a proportion of voids unfilled reduces their compacted density and makes them prone to segregation. Gap-graded mixes can be used either by necessity, as when only coarse aggregate and uniform sand are available [3] [7]

Aggregates gradation may lead to the following: (a) segregation of the mortar from the coarse aggregates; (b) bleeding of water below and around larger aggregates and on the surface of the concrete; (c) settling of aggregates, leaving paste in the top lift of the concrete; (d) need for chemical admixtures in order to restore workability to the concrete; (e) increased use of cement; (f) insufficient air entrainment and air void distribution; (g) excessive use of water; (h) high porosity of the hardened concrete; (i) high material costs; (j) reduced service life [3] [8].

Variability in coarse aggregate gradation results from mingling different particle size distributions among concrete batches and is very common on any construction project. This may be attributed to the aggregate source (s), the stock piling operation, or the method of concrete production. It becomes a costly activity for both the contractor and the producer of the aggregate to ensure a unique and workable gradation of the aggregate, so usually little attention is paid in achieving one. Moreover, researches have been done to explain the effect of gradation variability on the properties of concrete. Gambir [8] concluded that compressive strength is more greatly influenced by the variation in the gradation of smaller sizes of aggregates than of larger ones. They observed higher compressive strengths in gap-graded mixes than in dense graded mixes. In the case of Gambir [8], he studied the effects of using optimized coarse aggregate gradations, which combine practical and economic constraints with attempts to obtain a mix of sizes that will lead to improved workability, durability and strength. Their optimized gradations performed nearly identical to their controlled, dense-graded aggregate mix but outperformed near gap-graded mixes by 10 to $20 \%$ in compressive strength and by $15 \%$ in terms of water demand [9]. Oduroh et al [3] conducted experiments on the influence of the gradation on the strain-rate tensile behavior of the concrete. He observed that there was an inverse proportion between the uniaxial tensile strength and the maximum size of the aggregate particles at high strains. This was attributed to the fact that surface area increases with the decrease in the maximum size of the aggregates, which decreases the possibility of finding voids and results in the increase of the bond strength. Misshapen particles can be misleading during the grading of the aggregate. They sometimes appear to be finer when they actually are coarser and vice versa. Misleading gradations can decrease the workability of the concrete and increase the void space, thereby reducing the strength and durability of the concrete. They can also lead to an increase cement and water demand in order to fill these extra voids [10].

\section{Methodology}

Bryman [11] postulates that a research design is a plan, framework, structure and strategy of investigating a problem and coming out with answers that best solve the problem. It specifics the procedures necessary for obtaining the information needed to structure and/or solve a research problem. The research design employed in this study was the quantitative design, which was used to answer questions on relationships within measurable variables with an intention to ascertain and explain physical and mechanical properties of aggregate around Accra and its effect on the workability of concrete. Quantitative research is a method of inquiry employed in many different academic disciplines, traditionally in the social science and it also used in engineering fields that can then be used to seek empirical support for this research hypotheses which is:

To determine and asses the physio-mechanical properties of rocks aggregate in three leading quarry site around Accra.

\section{Experimental Programme/Data Collecting Procedure}

For the purpose of this research work, samples (coarse aggregate) were taken from three engineering quarry site for engineering evaluation test to ascertain their characteristic strengths. The three engineering quarry sites which have different types of coarse aggregate were: quartz mineral aggregate (igneous rock) from Geochina quarry site at Nsawam, sandstone mineral aggregate (metamorphic rock) from Dam side quarry site at Weija and quartzite mineral aggregate (sedimentary rock) from Art of God quarry site at Aburi. Before tests were carried out, three aggregate samples were fetched at different times and a lump of the three sample of rocks also taken from the parent rock site under consideration into sack and transported to the laboratories (AIT Civil Engineering laboratory) for test evaluation.

\subsection{Laboratory Analysis of Samples}

For the purpose of achieving the research objectives samples taken from the three sites were examined with respect to: specific gravity test, moisture content test, bulk density or unit weight and void ratio, grading of aggregates, water absorption test, porosity test, slump and aggregate compaction factor test, surface texture and weatherability. 
The figure 2 below shows pictorial nature of the crush coarse aggregate taken from Geochina quarry and the other study sites with their measurement taken using meter rule site for the laboratory test. Figure 3 also shows the specific samples taken from all the three sites

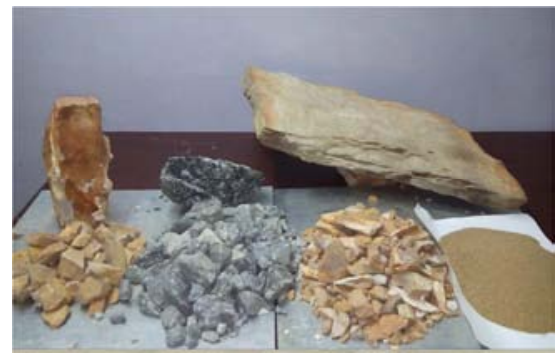

Figure 2. Typical rock sample worked on at the laboratries.

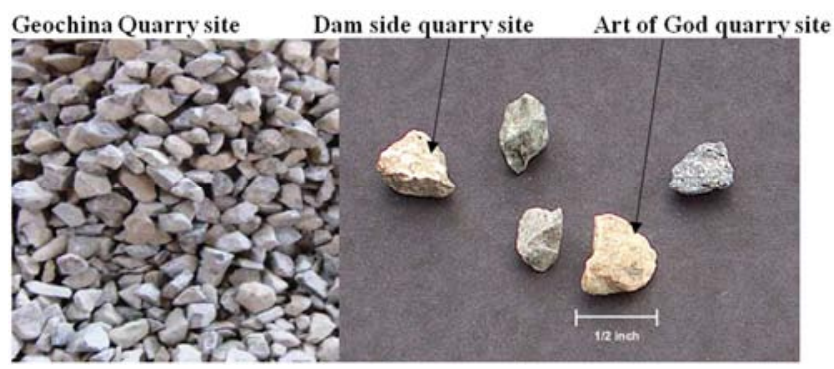

Figure 3. Rock aggregate samples from the various quarry sites.

Two set of laboratory experiment were done, one on the lump sample of the rock and the other is on the coarse aggregate sample. The experiment below were carry out on all the three minerals selected from the various rocks.

\subsection{Laboratory Test on Rock Quality Designation of Rock Core (ASTM D6032)}

This test was undertaken using ASTM D6032 [12] to ascertain the natural strength characteristic of undisturbed sample. The uncrushed rock samples were taken from the various parent rock from various quarry site and the under list tests was done (E691), detailed as follows:

Determination of rock material dry density (ASTM D2726) [13]

Determination of the (natural) water content of rock material (ASTM D2216) [14] [15]

Determination of porosity of rock material (ASTM D5084)

Determination of the compressive load strength of rock material (ASTM D7012) [16]

Determination of rock material toughness in the laboratory

\section{(ASTM 5873) [17]}

\subsubsection{Determination of Rock Material Dry Density (ASTM D2726)}

The objective of the test was to measure the dry density of samples of the rock. The dry density was expressed in units of mass ( $\mathrm{kg}$ or $\mathrm{g}$ ) per unit volume $\left(\mathrm{m}^{3}\right.$ or $\mathrm{cm}^{3}$ or $\left.\mathrm{mm}^{3}\right)$. Three specimens of regular form from a representative sample of the rock were prepared for the test. Following the prescribed laboratory procedure, the dry density for the samples was calculated according equation 1 as follows:

$$
\text { Dry density }=\frac{\text { dry mass }}{\text { volume }}=\frac{C-A}{V}\left(\text { in } \frac{\mathrm{kg}}{\mathrm{m} 3} \text { or } \frac{\mathrm{g}}{\mathrm{mm} 3}\right)
$$

(Dry unit weight $=\rho d \times 9.8\left(\right.$ in $\left.\mathrm{kN} / \mathrm{m}^{3}\right)$

$$
\begin{aligned}
& \text { Average Dry density for igneous rock } \\
& \qquad \begin{aligned}
& \frac{226 \mathrm{~g}-204 \mathrm{~g}}{4 \mathrm{~cm} \times 6 \mathrm{~cm} \times 8 \mathrm{~cm}}=\frac{22 \mathrm{~g}}{192 \mathrm{~cm}^{3}}=\frac{11}{96} \times 9.8 \\
& =1.123 \mathrm{~N} / \mathrm{cm}^{3}
\end{aligned}
\end{aligned}
$$

Based on the laboratory experiment, the following working calculations and results ensued

Average dry density for sedimentary rock $=1.57 \mathrm{~g} / \mathrm{cm}^{3}$

Average dry density for metamorphic rock $=2.03 \mathrm{~g} / \mathrm{cm}^{3}$

\subsubsection{Determination of the (Natural) Water Content of Rock Material (ASTM D2216) [14]}

The objective of this test was to determine the water content of the rock material as it was retrieved in the field. For the accurate determination of the in-situ water content, the sampling, storage, transport and handling precautions was taken such that the water content remains within $1 \%$ of the in situ value by covering the sample with airtight material [13]. Representative samples consist of 3 lumps three from various quarry sites were used. The calculation of the water content for each sample was determined from equation 2 as follows:

Water Content $(w)=\frac{\text { pore } \text { water mass }}{\text { sample mass }} \times 100 \%=\frac{B-C}{C-A} \times 100 \%$

Based on the working calculation from the laboratory experiment, the following were determined:

For igneous rock:

$A=1749 g$
$B=1783 g$
$C=1754 g$

Water Content $=\left[\frac{(1783 g-1754 g)}{(1754 g-1749 g)}\right]=5.8 g$

\begin{tabular}{|c|c|c|c|c|c|}
\hline \multirow[b]{2}{*}{ Item } & \multirow[b]{2}{*}{ Rock Type } & \multicolumn{2}{|c|}{ Natural Water Content } & \multicolumn{2}{|l|}{ Dry Density } \\
\hline & & $\begin{array}{l}\text { Sample Standard } \\
\text { Deviation }\end{array}$ & Average Water Content in grams & Sample Standard Deviation & $\begin{array}{l}\text { Average Dry Density } \\
\left(\mathrm{g} / \mathrm{cm}^{3}\right)\end{array}$ \\
\hline 1 & Igneous Rock & 1.98 & 5.80 & 0.0085 & $1.123 \mathrm{~g} / \mathrm{cm}^{3}$ \\
\hline 2 & Sedimentary & 1.46 & 6.11 & 0.096 & $1.57 \mathrm{~g} / \mathrm{cm}^{3}$ \\
\hline 3 & Metamorphic & 4.05 & 7.93 & 0.1402 & $2.03 \mathrm{~g} / \mathrm{cm}^{3}$ \\
\hline
\end{tabular}

Table 1. Shows the natural water content and Dry density of rock from the various quarries. 


\subsubsection{Determination of Porosity of Rock Material (ASTM D5084)}

The objective of the test was to measure the porosity of rock specimens taken from the quarry sites. Porosity is the volume of the pores in the rock expressed as a percentage of the total volume of the rock. Preparation of the three specimens of regular form from a representative sample of rocks was made. Based on the prescribed laboratory procedure, the calculations to ascertain the porosity of the samples were estimated as:

$$
\begin{gathered}
\text { Porosity } \%(n)=\frac{V v}{V} \times 100 \% \\
\text { Pore volume }(V v)=\frac{M s a t-M d r y}{\rho w}
\end{gathered}
$$

Where $\mathrm{Pw}=1.01 \mathrm{gm} / \mathrm{cc}$

$\mathrm{v}$ is volume of sample estimated as $98.18 \mathrm{~cm}^{3}$

$\mathrm{B}$ is mass of saturated specimen and container,

$\mathrm{A}$ is mass of dried clean container and $\mathrm{C}$ is the mass of dry clean specimen and container

$$
\text { Pore volume }(V v)=\frac{34 g-5 g}{1.01 g g / c c}=\frac{29 g}{1.01}=28.71 c c
$$

Porosity $(\phi)=\frac{\text { Pore Volume }}{\text { Total Volume }}=\frac{28.71}{98.18}=0.2924=29.24 \%$

Porosity in percentage of the various rock minerals material can be seen in the column three of the table 2 below. The saturated, initial dry mass and the volume of the pore is shown respectively of the rock samples.

Table 2. Tabulated Porosity of the Rocks.

\begin{tabular}{llllll}
\hline \multirow{2}{*}{ Item } & \multirow{2}{*}{ Rock Type } & Parameters & & & Porosity in percentage \\
\cline { 3 - 6 } & & $\mathbf{M}_{\text {sat }}(\mathbf{g})$ & $\mathbf{M s}(\mathbf{g})$ & 0.292 & $29.24 \%$ \\
& & 34 & 5 & 0.341 & $34.11 \%$ \\
2 & Igneous Rock & 37 & 1 & 0.417 & $41.66 \%$ \\
3 & Sedimentary & 42 & $\left.\mathbf{g} / \mathbf{c m}^{\mathbf{3}}\right)$ & \\
\hline
\end{tabular}

\subsubsection{Determination of the Compressive Load Strength of Rock Material (ASTM D7012)}

The compressive strength test is intended determine the strength classification of rock material. It may also be used to predict other strength parameters with which it is correlated. Based on the above laboratory procedure, the following calculation parameters of samples were determined.

Initial distance between the plates (A)
Compression distance between the plates (C)

Resistance load (L) in KN

The following

For igneous rock

$\mathrm{A}=14 \mathrm{~mm}$

$\mathrm{C}=13.81 \mathrm{~mm}$

\begin{tabular}{|c|c|c|c|c|c|c|c|}
\hline \multirow[b]{2}{*}{ Item } & \multirow[b]{2}{*}{ Rock Type } & \multicolumn{2}{|c|}{ Initial Distance Between Plates } & \multicolumn{2}{|c|}{ Compression Distance Between Plates } & \multicolumn{2}{|c|}{ Resistance Load } \\
\hline & & Standard Dev & $\begin{array}{l}\text { Initial distance between } \\
\text { plates (A) } \mathrm{mm}\end{array}$ & $\begin{array}{l}\text { Standard } \\
\text { Dev }\end{array}$ & $\begin{array}{l}\text { Compression distance } \\
\text { between plates }(C) \mathrm{mm}\end{array}$ & $\begin{array}{l}\text { Standard } \\
\text { Dev }\end{array}$ & $\begin{array}{l}\text { Average Resistance } \\
\text { load (L) KN }\end{array}$ \\
\hline 1 & Igneous Rock & 2.012 & $14 \mathrm{~mm}$ & 1.98 & $13.81 \mathrm{~mm}$ & 4.08 & $57 \mathrm{KN}$ \\
\hline 2 & Sedimentary & 1.08 & $12 \mathrm{~mm}$ & 1.66 & $11.73 \mathrm{~mm}$ & 2.66 & $29 \mathrm{KN}$ \\
\hline 3 & Metamorphic & 1.65 & $18 \mathrm{~mm}$ & 1.85 & $17.06 \mathrm{~mm}$ & 1.85 & $13 \mathrm{KN}$ \\
\hline
\end{tabular}

$\mathrm{L}=57 \mathrm{KN}$

Table 3. Compressive load strength of the Rocks.

\subsubsection{Determination of Rock Material Toughness in the Laboratory (ASTM 5873)}

The objective of the test was to determine the resistance of rock material against impact by a cork hammer. Samples needed for this test were in form of flat end faces, which are placed on the ground and following the test procedure. The average impact distances for the six samples were determined as follows:

Impact distance of the igneous rock $=802 \mathrm{~mm}$

Impact distance of the sedimentary rock $=602 \mathrm{~mm}$

Impact distance of the metamorphic rock $=201 \mathrm{~mm}$

\section{Laboratory Test on Coarse Aggregate from Rock}

The fine aggregate used for this research work was river bed sand collected from the River Densu at the outlet base of Weija Dam at Ga south local government area. The Densu River is a $116 \mathrm{~km}$ long river in Ghana with its source at the Atewa Range of the Eastern Region flowing through Accra and ends in an ecologically significant wetland at the edge of the Atlantic Ocean. The three types of coarse aggregate were obtained from the three study quarry factories located around Accra as follows: crush sandstone (from Artwork Quarry Site at Aburi, Crush quartz from Geochina Quarry site at Nsawam and crush quartzite from Dam Side Quarry site at Weija.

The following tests were carried out:

Specific gravity test and bulk density (ASTM C128) [18]

Moisture content test (ASTM C566) [19]; (ASTM D4404) [20]

Unit Weight and Void Ratio (ASTM D1556) [21]

Grading of Aggregates (ASTM C33) [22]

Test procedures: All these test procedures were in 
accordance with AASHTO and ASTM and it was done with all the three different coarse aggregate and fine aggregate.

\subsection{Specific Gravity and Bulk Density Test of Coarse Aggregate (ASTM C128)}

Specific gravity is the ratio of the weight of a given volume of a sample - coarse aggregate at a given temperature to weight of an equal volume of distilled water at that temperature both weights taken in air. The objective of the test was to determine the specific gravity of the coarse aggregates. In line with the above, a sample of $2000 \mathrm{~g}$ of the coarse aggregate was thoroughly washed to remove finer particles and dust, drained and then placed in the wire basket and immersed in distilled water at a temperature between $22^{\circ} \mathrm{C}$ to $32^{\circ} \mathrm{C}$. Following the prescribed laboratory procedures, the specific gravity, apparent specific gravity and water absorption for the samples were calculated as follows.

$\mathrm{A}=$ Oven - dry weight, was determined as $2282 \mathrm{~g}$

$\mathrm{B}=$ Saturated surface-dry weight (SSD), in grams mass, determined as $2360 \mathrm{~g}$

$\mathrm{C}=$ Weight of oven dry saturated sample, in grams, determined as $2179 \mathrm{~g}$

Bulk specific gravity (oven-dry basis),

$$
G s b=\frac{A}{B-C}
$$

Bulk specific gravity, (saturated surface-dry basis).

$$
G s b S S D=\frac{B}{(B-C)}
$$

Bulk specific gravity (Apparent),

$$
G s a=\frac{A}{(A-C)}
$$

Example of calculation from test results of sedimentary rock

$$
\begin{gathered}
\text { Oven }- \text { dry basis }(G s b)=\frac{2282 g}{2360 g-2179 g}=12.60 \\
\text { Saturated surface dry (Gsb)SSD }=\frac{2360 g}{2360 g-2179 g}=13.04 \\
\text { Bulk specific gravity(Apparent), Gsa }=\frac{2282 g}{(2282 g-1179 g)}=22.06 \text { (9) }
\end{gathered}
$$

Table 4. Specific gravity, absorption and bulk density of coarse aggregate.

\begin{tabular}{lllllll}
\hline \multirow{2}{*}{ Calculation Parameter } & Sedimentary & & Metamorphic & Igneous Rock \\
\cline { 3 - 6 } & Standard Dev & Average Value & Standard Dev & Average Value & Standard Dev & Average Value \\
\hline 1 & Oven-dry basis (Gsb) & 0.85 & 12.60 & 0.34 & 10.62 & 0.787 \\
2 & SSD (Gsb) & 0.99 & 13.04 & 0.48 & 11.44 & 7.06 \\
3 & Apparent (Gsa) & 1.35 & 22.16 & 1.156 & 17.11 & 7.30 \\
4 & Water Absorption & 2.56 & $10.25 \%$ & 1.08 & $14.16 \%$ & 0.867 \\
\hline
\end{tabular}

\subsection{Moisture Content Test}

The objective of this test was to determine the moisture content of the coarse aggregate sample by oven drying using samples of various coarse aggregates picked from the field of study. Following the prescribed test procedure, the percentage of water absorption was calculated as:

$$
\text { Moisture Content in } \%=\left[\frac{(W 2-W 3)}{(W 3)}\right]
$$

Where weight of empty container $=\mathrm{W} 1=7 \mathrm{~g}$

Weight of soaked aggregate + Weight of container, W2 =
$1312 \mathrm{~g}$.

Weight of oven dried aggregate + Weight of container, W3 $=1177 \mathrm{~g}$

Example absorption for metamorphic rock was calculated

\begin{tabular}{|c|c|c|c|c|c|c|c|}
\hline \multirow{2}{*}{\multicolumn{2}{|c|}{ Calculation Parameter }} & \multicolumn{2}{|l|}{ Sedimentary } & \multicolumn{2}{|l|}{ Metamorphic } & \multicolumn{2}{|l|}{ Igneous Rock } \\
\hline & & Standard Dev & Average Value & Standard Dev & Average Value & Standard Dev & Average Value \\
\hline 1 & Weight of empty container $=\mathrm{W} 1$ & 2.85 & 7 & 2.56 & 7 & 2.77 & 7 \\
\hline 2 & $\begin{array}{l}\text { Weight of soaked aggregate }+ \\
\text { Weight of container }=\mathrm{W} 2\end{array}$ & 29.54 & 1010 & 31.33 & 1326 & 30.86 & 1186 \\
\hline 3 & $\begin{array}{l}\text { Weight of oven dried aggregate }+ \\
\text { Weight of container }=\mathrm{W} 3\end{array}$ & 14.87 & 772 & 27.99 & 1312 & 28.46 & 1080 \\
\hline 4 & Moisture Content in \% & 096 & $7.6 \%$ & 1.43 & $10.7 \%$ & 0.89 & $8.1 \%$ \\
\hline
\end{tabular}
as

Moisture Content in $\%=\left[\frac{(1312 g-1177)}{(1177)}\right]=0.1073 g \times 100=10.7 \%$

The table 5 below depicts the compilation of moisture content of the coarse aggregates when soaked in distilled water for twenty-four hours under observation.

Table 5. Aggregate Moisture Content.

\subsection{Moisture Content Test of Coarse Aggregate}

The natural moisture content of an aggregate is the ratio of the weight of the coarse aggregate in a given mass of sample which is expressed in percentage, it also refers to the presence of water in the pores and on the surface of aggregates. Four different moisture conditions of an aggregate is acknowledged: 
Oven Dry (OD): This condition is obtained by keeping aggregates at temperature of $110^{\circ} \mathrm{C}$ for a period of time long enough to reach a constant weight.

Air Dry (AD): This condition is obtained by keeping aggregates under room temperature and humidity. Pores inside the aggregate are partly filled with water.

Saturated Surface Dry (SSD): In this situation the pores of the aggregate are fully filled with water and the surface is dry. This condition can be obtained by immersion in water for 24 hours following by drying of the surface with wet cloth.

Wet (W): The pores of the aggregate are fully filled with water and the surface of aggregate is covered with a film of water.

For the purpose of this laboratory work, the initial gross weight of sample and metal container was determined. The samples were then oven dried continuously at temperature at $110^{\circ} \mathrm{C}$ in an oven to a constant weight. Over 90 percent of the moisture was lost in the sample within 4 to 5 hours and period 15 to 24 hours was used to obtain required to a constant weight. The dry weight after drying the sample and container was immediately taken.

\subsection{Unit Weight and Void Ratio (ASTMD 1556)}

The objective of this test was to determine the unit weight and voids of coarse aggregate using a $2000 \mathrm{~g}$ of coarse aggregate. To undertake the above laboratory works, the weight of water at room temperature required to fill the metal cylinder was determined. The sample was dry to a constant weight at $110^{\circ} \mathrm{C}$ and thoroughly mixed. It was then left to cool at a room temperature. The measuring cylinder was $1 / 3$ full and it was then rod with temping rod throughout the surface with 25 strokes. The rodding operation was done to evenly distribute it over the surface. The cylinder was $2 / 3$ full and the rodding operation was repeated. The cylinder was filled to overflowing levels and again rodded with 25 strokes. The surplus aggregate was struck off by using the same the tamping rod as a straight edge. The net weight of sample was determined from the weight of sample plus measure $(\mathrm{G})$ and the weight of measure alone, $(\mathrm{T})$. The test was undertaken thrice at which the results of samples taken were measured and values were averaged. Results from the same sample were calculated as follows:

The unit weight, $M$ was calculated from the weight of sample and the volume of measure, $\mathrm{V}$ as follows:

$$
M=G-\frac{T}{V}
$$

The unit weight was determined by the test method for aggregate in an oven-dry condition. The SSD unit weight, $\mathrm{M}_{\text {ssd }}$ can be calculated as:

$$
\text { Mssd }=M\left(1+\frac{A}{100}\right)
$$

Where $\mathrm{A}=$ absorption $(\%)$

The void content was calculated from the unit weight, $M$ and bulk specific gravity (oven-dry basis) associated with the density of water, $\mathrm{W}$ as follows:

$$
\operatorname{Voids}(\%)=\frac{(S x W)-M}{(S x W) \times 100}
$$

\subsection{Grading of Aggregates (ASTM C1716)}

The objective of this test was to attempt to determine the relative proportions of different grain size which make up a given sample mass taken from various quarry sites. This method is used primarily to determine the grading of materials proposed for use as aggregates or being used as aggregate. The results are used to determine compliance of the particle size distribution with applicable specification requirements, and to provide necessary data for control of the production of various aggregate products and mixture concrete which contains aggregate. The results may also be useful in developing relationships concerning porosity and packing. Material used for this test was coarse aggregate retained in a sieve $4.75 \mathrm{~mm}$. A sample of coarse aggregate was obtained by means of the method of quartering. The sample was air dried to obtain it in a surface dry state. The aggregate sample was placed in a set of standard screen and place in a mechanical shaker. The sample was screened until not more than $1 \%$ of the residue passes any screen during a period of 1 minute shaking. The material retained on the any of the screen was weighed separately. After weighing, the material on each screen was recorded as D. The cumulative weights on all screens were converted into percentages of the total weight. Table 6 below displays results of the fine and coarse aggregate particle size distribution of the three main quarry site considered for research this research work.

Table 6. Particle size distribution of the igneous rock aggregates from Geochina Quarry site at Nsawam.

\begin{tabular}{lllll}
\hline IS Sieve Size & Weight of Aggregate Retained & $\begin{array}{l}\text { Percentage of total Aggregate } \\
\text { Retained }\end{array}$ & $\begin{array}{l}\text { Cumulative of Aggregate } \\
\text { Retained }\end{array}$ & $\begin{array}{l}\text { Percentage of Aggregate } \\
\text { Retained }\end{array}$ \\
\hline $53 \mathrm{~mm}$ & - & - & - & 100 \\
$37.5 \mathrm{~mm}$ & 90.00 & 9.00 & 9.00 & 91.00 \\
$31.5 \mathrm{~mm}$ & 178.00 & 1.78 & 26.80 & 73.20 \\
$26.5 \mathrm{~mm}$ & 288.00 & 2.88 & 55.60 & 44.40 \\
$19 \mathrm{~mm}$ & 162.00 & 1.62 & 71.80 & 28.20 \\
$16 \mathrm{~mm}$ & 187.00 & 1.87 & 90.50 & 9.50 \\
$13.2 \mathrm{~mm}$ & 52.00 & 5.20 & 95.70 & 4.30 \\
$9.5 \mathrm{~mm}$ & 32.00 & 3.20 & 98.90 & 1.10 \\
$4.75 \mathrm{~mm}$ & 11.00 & 1.10 & 100 & 0.00 \\
$2.36 \mathrm{~mm}$ & 0.00 & 0.00 & 0.00 & 0.00 \\
$1.18 \mathrm{~mm}$ & 0.00 & 0.00 & 0.00 & 0.00 \\
\hline
\end{tabular}




\begin{tabular}{lllll}
\hline IS Sieve Size & Weight of Aggregate Retained & $\begin{array}{l}\text { Percentage of total Aggregate } \\
\text { Retained }\end{array}$ & $\begin{array}{l}\text { Cumulative of Aggregate } \\
\text { Retained }\end{array}$ & $\begin{array}{l}\text { Percentage of Aggregate } \\
\text { Retained }\end{array}$ \\
\hline $0.6 \mathrm{~mm}$ & 0.00 & 0.00 & 0.00 & 0.00 \\
$0.3 \mathrm{~mm}$ & 0.00 & 0.00 & 0.00 & 0.00 \\
$0.15 \mathrm{~mm}$ & 0.00 & 0.00 & 0.00 & 0.00 \\
$0.075 \mathrm{~mm}$ & 0.00 & 0.00 & 0.00 & 0.00 \\
Pan & 0.00 & 0.00 & 0.00 & 0.00 \\
\hline
\end{tabular}

Table 7. Particle size distribution of the Sedimentary rock aggregate from Art of God Quarry site at Aburi.

\begin{tabular}{lllll}
\hline IS Sieve Size & Weight of Aggregate Retained & $\begin{array}{l}\text { Percentage of total Aggregate } \\
\text { Retained }\end{array}$ & $\begin{array}{l}\text { Cumulative of Aggregate } \\
\text { Retained }\end{array}$ & $\begin{array}{l}\text { Percentage of Aggregate } \\
\text { Retain }\end{array}$ \\
\hline $37.5 \mathrm{~mm}$ & - & - & - & 100.00 \\
$31.5 \mathrm{~mm}$ & 72.49 & 7.24 & 7.24 & 92.76 \\
$26.5 \mathrm{~mm}$ & 204.50 & 20.45 & 27.69 & 72.31 \\
$19 \mathrm{~mm}$ & 47.30 & 4.73 & 32.42 & 67.58 \\
$16 \mathrm{~mm}$ & 171.40 & 17.14 & 49.50 & 50.48 \\
$13.2 \mathrm{~mm}$ & 166.90 & 16.69 & 66.25 & 33.75 \\
$9.5 \mathrm{~mm}$ & 33.50 & 3.35 & 69.60 & 30.40 \\
$4.75 \mathrm{~mm}$ & 304.00 & 30.40 & 100.00 & 0.00 \\
$2.36 \mathrm{~mm}$ & 0.00 & 0.00 & 0.00 & 0.00 \\
$1.18 \mathrm{~mm}$ & 0.00 & 0.00 & 0.00 & 0.00 \\
$0.6 \mathrm{~mm}$ & 0.00 & 0.00 & 0.00 & 0.00 \\
$0.3 \mathrm{~mm}$ & 0.00 & 0.00 & 0.00 & 0.00 \\
$0.15 \mathrm{~mm}$ & 0.00 & 0.00 & 0.00 & 0.00 \\
$0.075 \mathrm{~mm}$ & 0.00 & 0.00 & 0.00 & 0.00 \\
Pan & 0.00 & 0.00 & 0.00 & 0.00 \\
\hline
\end{tabular}

Table 8. Particle size distribution of the metamorphic rock aggregates from Dam Side Quarry site at Weija.

\begin{tabular}{lllll}
\hline IS Sieve Size & Weight of Aggregate Retained & $\begin{array}{l}\text { Percentage of total Aggregate } \\
\text { Retained }\end{array}$ & $\begin{array}{l}\text { Cumulative of Aggregate } \\
\text { Retained }\end{array}$ & $\begin{array}{l}\text { Percentage of Aggregate } \\
\text { Retain }\end{array}$ \\
\hline $53 \mathrm{~mm}$ & - & - & - & 100.00 \\
$37.5 \mathrm{~mm}$ & - & - & - & 100.00 \\
$31.5 \mathrm{~mm}$ & 30.00 & 3.00 & 3.00 & 97.00 \\
$26.5 \mathrm{~mm}$ & 80.00 & 8.00 & 11.00 & 89.00 \\
$19 \mathrm{~mm}$ & 411.00 & 41.10 & 52.10 & 47.90 \\
$16 \mathrm{~mm}$ & 187.00 & 18.70 & 70.80 & 29.20 \\
$13.2 \mathrm{~mm}$ & 130.00 & 13.00 & 83.80 & 16.20 \\
$9.5 \mathrm{~mm}$ & 91.00 & 9.10 & 92.90 & 7.10 \\
$4.75 \mathrm{~mm}$ & 71.00 & 7.10 & 100 & 0.00 \\
$2.36 \mathrm{~mm}$ & 0.00 & 0.00 & 0.00 & 0.00 \\
$1.18 \mathrm{~mm}$ & 0.00 & 0.00 & 0.00 & 0.00 \\
$0.6 \mathrm{~mm}$ & 0.00 & 0.00 & 0.00 & 0.00 \\
$0.3 \mathrm{~mm}$ & 0.00 & 0.00 & 0.00 & 0.00 \\
$0.15 \mathrm{~mm}$ & 0.00 & 0.00 & 0.00 & 0.00 \\
$0.075 \mathrm{~mm}$ & 0.00 & 0.00 & 0.00 & 0.00 \\
Pan & 0.00 & 0.00 & 0.00 & 0.00 \\
\hline
\end{tabular}

Table 9. Particle size distribution of the fine aggregates from Densu River at Weija.

\begin{tabular}{lllll}
\hline IS Sieve Size & Weight of Aggregate Retained & $\begin{array}{l}\text { Percentage of total Aggregate } \\
\text { Retained }\end{array}$ & $\begin{array}{l}\text { Cumulative of Aggregate } \\
\text { Retained }\end{array}$ & $\begin{array}{l}\text { Percentage of Aggregate } \\
\text { Retain }\end{array}$ \\
\hline $53 \mathrm{~mm}$ & - & - & - & - \\
$37.5 \mathrm{~mm}$ & - & - & - & - \\
$31.5 \mathrm{~mm}$ & - & - & - & - \\
$26.5 \mathrm{~mm}$ & - & - & - & - \\
$19 \mathrm{~mm}$ & - & - & - & - \\
$16 \mathrm{~mm}$ & - & - & - & - \\
$13.2 \mathrm{~mm}$ & - & - & - & - \\
$9.5 \mathrm{~mm}$ & - & - & - & - \\
$4.75 \mathrm{~mm}$ & - & - & - & - \\
$2.36 \mathrm{~mm}$ & 0.00 & 0.00 & 0.00 & 100.00 \\
$1.18 \mathrm{~mm}$ & 0.00 & 0.00 & 0.00 & 53.20 \\
$0.6 \mathrm{~mm}$ & 468.00 & 46.80 & 46.80 & 12.40 \\
$0.3 \mathrm{~mm}$ & 408.00 & 40.80 & 87.60 & 1.90 \\
$0.15 \mathrm{~mm}$ & 105.00 & 10.50 & 98.10 & \\
\hline
\end{tabular}




\begin{tabular}{lllll}
\hline IS Sieve Size & Weight of Aggregate Retained & $\begin{array}{l}\text { Percentage of total Aggregate } \\
\text { Retained }\end{array}$ & $\begin{array}{l}\text { Cumulative of Aggregate } \\
\text { Retained }\end{array}$ & $\begin{array}{l}\text { Percentage of Aggregate } \\
\text { Retain }\end{array}$ \\
\hline $0.075 \mathrm{~mm}$ & 19.00 & 1.90 & 100.00 & 0.00 \\
Pan & 0.00 & 0.00 & 100.00 & 0.00 \\
\hline
\end{tabular}

\section{Data Analysis and Discussions}

\subsection{Results on Rock Lumps}

Several laboratory tests were conducted on the rock samples to ascertain their strength. The tables 10 and 11 below are a summary of the results obtained from the series of laboratory experiment conducted. It can be deduced from column two $\mathrm{C}_{2}$ that metamorphic rock has the highest natural water content of $793 \mathrm{~g}$ followed by sedimentary rock of $611 \mathrm{~g}$ and igneous of $580 \mathrm{~g}$. This characteristic can certainly be deduced from their porosity results. Air spaces in the rock samples with the valued percentage porosity of $8.6 \%, 7.4 \%$ and $8.6 \%$ respectively in the column $\mathrm{C}_{3}$ were deduced, by extension; the higher the porosity, the higher the water content. The third column $\mathrm{C}_{4}$, shows the summary results of the dry density of the rock samples. Again, the void space is directly proportional to the dry density; so the higher the void space, the higher the dryness of the rock. Since the void space is high in the metamorphic rock sample, the ability to dehydrate is more hence it has highest drying density with valve of $2.03 \mathrm{~N} / \mathrm{cm}^{3}$. Sedimentary and igneous rock had values of $1.57 \mathrm{~N} / \mathrm{cm}^{3}$ and $1.12 \mathrm{~N} / \mathrm{cm}^{3}$ reactively.

The column $\mathrm{C}_{5}$ and $\mathrm{C}_{6}$ of table 8 shows the impact and load resistivity of the rocks strength. It was experimentally observed that igneous rock has the highest resistance with $802 \mathrm{~mm}$ in rebounds load blow distance with $57 \mathrm{KN}$ compressive load resistance followed by sedimentary rocks with $602 \mathrm{~mm}$ resistance with $29 \mathrm{kn}$ of and metamorphic rock being the least with $201 \mathrm{~mm}$ and $13 \mathrm{kn}$. From column $\mathrm{C}_{5}$, igneous rock impact rebounds load blow distance is highest as a result of strong interlocking bond surface particles of themselves so when an external load hit on it, its resistance produce a high distance with $802 \mathrm{~mm}$ followed by the rest of the rocks with $602 \mathrm{~mm}$ and $201 \mathrm{~mm}$. With the same approximate size of the rock lump under mechanical compression cube crushing machine, sedimentary rock resisted $29 \mathrm{kn}$ of load which is higher than $13 \mathrm{kn}$ from metamorphic but less to igneous rock of $57 \mathrm{kn}$ in column $\mathrm{C}_{6}$. These load variations came as a result of the interlocking compatibility of the rocks and reaction of the rock lump both the internal and the external. Although all the rock sample are good material for construction concrete work, metamorphic rock was crushed with less applied force which shows that the porosity of the rocks varies and it has an effect on their strength. Comparing between igneous rock and sedimentary rock, the load difference is $28 \mathrm{kn}$ approximately twice as strength of sedimentary rock as igneous rock and it shows that igneous is less permeable hence highest strength.

Table 10. Summary Test results on the rock.

\begin{tabular}{llllll}
\hline \multirow{2}{*}{ Rock Type } & \multicolumn{2}{l}{ Calculated table results } & & \\
\cline { 2 - 6 } & $\begin{array}{l}\mathbf{C}_{\mathbf{2}} \text { Natural water } \\
\text { content (g) }\end{array}$ & $\mathbf{C}_{\mathbf{3}}$ Porosity \% & $\mathbf{C}_{\mathbf{4}}$ Dry density $\left(\mathbf{g} / \mathbf{c m}^{\mathbf{3}}\right.$ ) & $\begin{array}{l}\mathbf{C}_{\mathbf{5}} \text { Impact } \\
\text { resistance (mm) }\end{array}$ & $\begin{array}{l}\mathbf{C}_{\mathbf{6}} \text { Resistance load } \\
(\mathbf{L}) \mathbf{K N}\end{array}$ \\
\hline Igneous rock & 580 & 29 & 1.12 & 802 & $57 \mathrm{KN}$ \\
Sedimentary rock & 611 & 34 & 1.57 & 602 & $29 \mathrm{KN}$ \\
Metamorphic rock & 793 & 41 & 2.03 & 201 & $13 \mathrm{KN}$ \\
\hline
\end{tabular}

\subsection{Results on Coarse Aggregate from of Rock}

Base on the various laboratory test conducted on the sample from the three main quarry site around Accra, it has been proven that the rock samples display varying physical and mechanical properties as an indication of the durability of the construction material for construction projects from table 11 . The table 12 below shows the results of particle size distribution carried out on the various aggregates (coarse and fine). The coarse and fine aggregate maximum sizes used for the study ranges from 53 to $4.75 \mathrm{~mm}$ (D5519) and $4.75 \mathrm{~mm}$ to $0.00 \mathrm{~mm}$ (D4222) ended in the pan. The coarse aggregates were irregular in shape. The size of the aggregate used for this experiment ranges from the particles that passed through $19 \mathrm{~mm}$ sieve and retained in $9.5 \mathrm{~mm}$ and the sand that serve as fine aggregate was used in passing through $4.75 \mathrm{~mm}$ to $0.0075 \mathrm{~mm}$. The aggregate, crush igneous, crush sedimentary and crush metamorphic have specific gravity of 2.70, 2.60 and 2.67 respectively.

Table 11. Physical and mechanical properties of the three coarse aggregate from the quarry sites.

\begin{tabular}{llll}
\hline \multirow{2}{*}{ Property } & Values & & Metamorphic \\
\cline { 2 - 4 } & Igneous & Sedimentary & $14.1 \%$ \\
\hline Water absorption and porosity & $15.88 \%$ & $8.30 \%$ & 2.67 \\
Apparent specific gravity & 2.70 & 2.60 & $10.7 \%$ \\
Moisture content & $7.6 \%$ & $7.6 \%$ & 2.67 \\
Specific gravity & 2.70 & 2.60 & \\
\hline
\end{tabular}


Table 12. Particle size distribution of coarse and fine aggregates (ASTM D6913) [23].

\begin{tabular}{lllll}
\hline \multirow{2}{*}{ Sieve size in mm } & \multicolumn{3}{l}{ Aggregates percentage fineness by mass, (\% passing) } \\
\cline { 2 - 5 } & Igneous rock - crush & Sedimentary - crush & Metaphoric rock - crush & Sand - fine \\
\hline $53 \mathrm{~mm}$ & 100 & 100 & 100.00 & - \\
$37.5 \mathrm{~mm}$ & 91.00 & 100.00 & 100.00 & - \\
$31.5 \mathrm{~mm}$ & 73.20 & 92.76 & 97.00 & - \\
$26.5 \mathrm{~mm}$ & 44.40 & 72.31 & 89.00 & - \\
$19 \mathrm{~mm}$ & 28.20 & 67.58 & 47.90 & - \\
$16 \mathrm{~mm}$ & 9.50 & 50.48 & 29.20 & - \\
$13.2 \mathrm{~mm}$ & 4.30 & 33.75 & 16.20 & - \\
$9.5 \mathrm{~mm}$ & 1.10 & 30.40 & 7.10 & - \\
$4.75 \mathrm{~mm}$ & 0.00 & 0.00 & 0.00 & - \\
$2.36 \mathrm{~mm}$ & 0.00 & 0.00 & 0.00 & 100.00 \\
$1.18 \mathrm{~mm}$ & 0.00 & 0.00 & 0.00 & 100.00 \\
$0.6 \mathrm{~mm}$ & 0.00 & 0.00 & 0.00 & 53.20 \\
$0.3 \mathrm{~mm}$ & 0.00 & 0.00 & 0.00 & 12.40 \\
$0.15 \mathrm{~mm}$ & 0.00 & 0.00 & 0.00 & 1.90 \\
$0.075 \mathrm{~mm}$ & 0.00 & 0.00 & 0.00 & 0.00 \\
Pan & 0.00 & 0.00 & 0.00 & 0.00 \\
\hline
\end{tabular}

Natural aggregate is often made up of a mixture of particles that do not fall entirely within only one of the size ranges covering two or more categories in accordance with D2487 of soil classification. It would be too tedious to count individual particle size because of the enormous number. Therefore, the grain distribution curve is use to find the properties of the aggregate. The result from table 9 above is for the summary of sieve analysis laboratory experiment on the aggregate shown in figure 4 and 5 below. The grain size distribution curve shown in figure 4 below represent the results of column 2, 3, 4 of the coarse aggregate above and figure 5 below represent column 5 above which is the fine aggregate on table 11 .

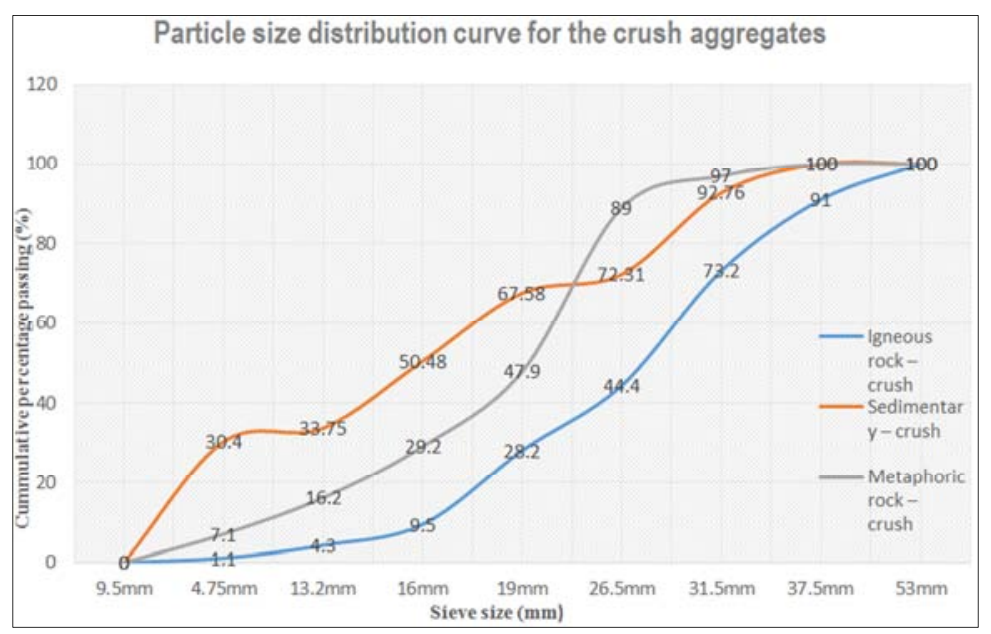

Figure 4. Particle Size Distribution For Crush Aggregates.

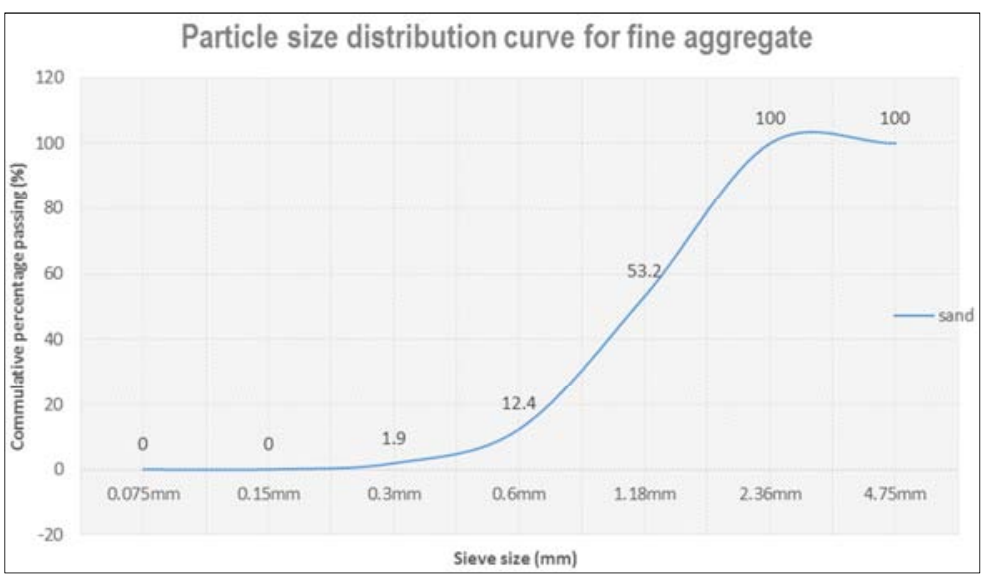

Figure 5. Particle Size Distribution Curve For The Fine Aggregate. 
The grading curve for all the aggregate fell within the lower and upper limit of the grading chart requirement for aggregate natural source BS 882 (1992). This implies that all the aggregate are suitable for construction work. However, the grading curve for crushed igneous rock (figure 4) shows a reasonable deviation out from the gradation limit and a significant portion of the curve is lower limit requirement. Such aggregates require fines to achieve reasonable workability. The metamorphic crush aggregate (figure 4) on the distribution curve shows a uniform graded aggregate. In accordance with particle size distribution chart, a uniform graded aggregate is where most of the particles are approximately the same size which shows an approximate vertical curve. Inferring from figure 4 on the distribution curve, most of the particles of metamorphic rocks are located between sieve $13.2 \mathrm{~mm}$ and $26.5 \mathrm{~mm}$. Sedimentary crushed aggregate is most preferable aggregate, the particles size distribution curve of the crushed sedimentary aggregate shows a well graded particle among them observing from the figure 5. A well-graded aggregate contains a wide range of appreciable particles size which is distributed evenly across the graph.

The fine aggregate in the figure 5 shows a deviation characteristic outside the recommended range aggregate curve. The distributed curve shows that most of the aggregate are located between sieve size of $0.3 \mathrm{~mm}$ and $2.36 \mathrm{~mm}$ which depict an unstable aggregate [23]. This further buttresses the point that the crushed coarse aggregate are equally good for construction but the fine aggregate require compaction to obtain durable concrete matrix.

\section{Conclusions and Recommendations}

Previous works by [24] and [25] confirm that both the physical and mechanical properties of rocks have varying degrees of influence (drying shrinkage, creep and temperature) on the coarse aggregate from which they are produced and hence eventually affecting the strength of concrete produced from this aggregates. The purpose of this test was to determine the durability and strength which explain the physical and mechanical properties of coarse aggregates obtained around Accra.

It can be concluded that there is a direct correlation between the volume of air spaces in the rock sample, its dry density, porosity and the water content in the rock. A sample of igneous rock recorded a dry density of $1.123 \mathrm{~g} / \mathrm{cm}^{3}$ with $6.75 \%$ air spaces and $580 \mathrm{~g}$ of water compared with metamorphic rock which recorded $8.6 \%$ air spaces has high water content of $793 \mathrm{~g}$, average dry density of $2.03 \mathrm{~g} / \mathrm{cm}^{3}$ and pore per volume of $0.41 \mathrm{~g} / \mathrm{ml}$. The above physio-mechanical property places igneous rock superior to sedimentary and metamorphic rocks when it comes to hygroscopic features. Sedimentary rocks had an average water content of $611 \mathrm{gm}$ per sample with a corresponding average density of $1.57 \mathrm{~g} / \mathrm{cm}^{3}$ and porosity of $7.4 \%$. Thus this aggregate would absorb more water compared to igneous rocks, thus affecting the strength of concrete products resulting from this rock type when its features are not factored during the mix design process.

Correspondingly igneous rocks had the highest load resistance of $57 \mathrm{kn}$ almost twice the load resistance of sedimentary rock and more than four times the load resistance of metamorphic rocks. Similarly the igneous rocks proved superiority in terms of toughness with an impact distance of $802 \mathrm{~mm}$ more than four times that of metamorphic rocks.

It can be concluded that the grading curves for all aggregates fall within the lower and upper limit of the grading chart hence can be suitable for concrete work according to BS 882 (1992). Igneous rock however shows deviations out of the grading limits. Hence such aggregates would require fineness to achieve reasonable workability. Since a well-graded aggregate contains a wide range of appreciable particles size which distribute evenly across the graph, the sedimentary crush aggregate would be the most preferred choice in terms of particle size distribution.

Summarily curtailed, the physio-mechanical properties of parent rock which has a direct correlation with the rock aggregates shows that the igneous rocks is the most stable in terms of porosity, toughness and load resistance. The metamorphic rock on the other hand has proven to be the poorest in terms of physio-mechanical properties amongst the three. In terms of particle size grading, sedimentary rock has been shown to be well graded aggregate containing appreciable particle size distribution evenly distributed across the graph hence the best choice in terms of workability for the production of concrete.

\section{References}

[1] Wilberforce S. Buertey J. (2105), an examination of the effect of the physio-mechanical properties of concrete. Unpublished MEng Thesis submitted to the Open University of Malaysia (2015).

[2] Rogers, C. A., and Senior, S. A., "Recent Developments in Physical Testing of Aggregates to Ensure Durable Concrete," Advances in Cement and Concrete, Proceedings of Engineering Foundation Conference, American Society of Civil Engineers, 1994.

[3] Oduroh, P. K., Mahboub, K. C., and Anderson, R. M. (2000) Flat and elongated aggregates in Super pave regime. Journal of Materials in Civil Engineering, 12, 124-130.

[4] BS 812; (1995) Methods for Sampling and Testing of Mineral Aggregates, Sands and Fillers, British Standard Institute.

[5] Jackson, N. and Ravindra, K. D. (1996) Civil Engineering Materials (fifth edition), Macmillian Press Publishers Ltd. London, UK.

[6] ASTM C 88 - 99a Standard Test Method for Soundness of Aggregates by Use of Sodium Sulfate or Magnesium Sulfate

[7] Coarse Aggregate Performance in Ontario," Transportation Research Record 1301, Transportation Research Board, National Research Council, pp. 97- 106, 1991. 
[8] Gambir M. L., Concrete Technology, 3rd Edition, McGrawHill Publishing Companies, New Delhi 2006.

[9] Canadian Standards Association (CSA), Concrete Materials and Methods of Concrete Construction/Methods of Test for Concrete, A23. 1-00/A23. 2-00, 2000.

[10] Salihu, A. Y. (2011) Importance of Concrete Mix Design Quality Control Measure, Journal of Engineering and Applied Sciences, Cenresin Publications.

[11] Bryman, A. (2004). Social Research Methods. [2nd Ed]. Oxford: Oxford University Press.

[12] ASTM D 6032, (2012) Standard Test Methods for Rock Quality Designation of Rock Core, American Concrete Institute.

[13] Standard Test Methods for Determination of rock material dry density (ASTM D2726-96).

[14] Standard Test Methods for Laboratory Determination of Water (Moisture) Content Rock by Mass ASTM D2216-10.

[15] Standard Test Methods for Laboratory Determination of porosity of rock material (ASTM D5084).

[16] Standard Test Methods for Laboratory Determination of the compressive load strength of rock material (ASTM D7012).

[17] Standard Test Methods for Laboratory Determination of rock material toughness in the laboratory (ASTM D5873).
[18] Standard Test Methods for Laboratory determination of Specific gravity test, Water absorption test and bulk density (ASTM C128).

[19] Standard Test Methods for Laboratory determination of Moisture content test (ASTM C566).

[20] Standard Test Methods for Laboratory determination of Porosity test (ASTM D4404).

[21] Standard Test Methods for Laboratory determination of Unit Weight and Void Ratio (ASTM D1556).

[22] Standard Test Methods for Grading of Aggregates (ASTM C33) and (ASTM C1716).

[23] Standard Test Methods for determination of Particle size distribution of coarse and fine aggregates (ASTM D6913).

[24] Neville A. M., Properties of Concrete, ELSB 5th Edition, Pearson Education Publishing Ltd. London 2005.

[25] American Association of State Highway and Transportation Officials (AASHTO), AASHTO Guide Specification for Highway Construction, Section 56X, "Portland Cement Concrete Resistant to Excessive Expansion Caused by AlkaliSilica Reaction," http://leadstates.tamu.edu/ASR/library/gspec.stm, 2000. 